\title{
Acculturation Strategy and Racial Group in the Perception of Immigrants
}

\author{
Yvette D. Alcott and Susan E. Watt \\ University of New England, Armidale, New South Wales, Australia
}

\begin{abstract}
W e investigated the effects of race and different acculturation strategies on perceptions of immigrants in Australia, an immigrant-based nation with a multicultural policy. Two experimental studies presented participants with scenarios that systematically varied racial group (African, Asian, and European) and acculturation strategy (assimilation, integration, separation, marginalisation), then assessed responses to immigrant targets using measures of warmth, competence, affect, and cultural distance. Attitudes were significantly more positive towards targets who either integrated or assimilated, and negative towards targets who separated. This was regardless of the racial group being assessed, supporting the prediction that acculturation strategy is a stronger influence than race on perceptions of immigrants.
\end{abstract}

Keywords: acculturation, race, categorisation, multiculturalism

With today's global migration and ever-expanding multiracial and multicultural societies, the saying 'Don't judge a book by its cover' is ever more appropriate. Categorisation by race is an automatic and heuristic cognitive process (Kurzban, Tooby, \& Cosmides, 2001). However, in modern immigrant nations and pluralistic societies, a person's apparent racial group does not necessarily impart information about their nationality or cultural heritage. Assessing someone on race can therefore lead to gross generalisations, incorrect stereotyping, racial prejudice, and discrimination.

Racial prejudice and discrimination are continuing global phenomena, although race as a concept is a contentious issue. The United States' census still categorises individuals separately by race, although modern scientific research has demonstrated that, genetically, the differences between groups are smaller than those within groups, supporting that 'race' cannot be biologically differentiated (Bamshad et al., 2003). However, it is included as one of the three 'primary categories' (age, race, and gender) upon which people make immediate judgments about others (Kurzban et al., 2001). Often because a person is of a particular racial appearance, they are bestowed with the consensual cultural stereotypes associated with that racial group and subsequent prejudices of the perceiver (Kawakami, Dion, \& Dovidio, 1998). The term 'race' is still used widely in popular vernacular to categorise others, and the current article uses the term in this sense, rather than referring to it as a supported scientific concept. The current research investigated whether visibly distinct racial minorities are assessed and judged on their apparent racial group, or whether the acculturation strategies they use to adapt to their new country are more influential on the perceptions of the host population.

Acculturation is the process of change that groups of individuals go through when they are in continuous firsthand contact with groups of individuals who have different cultures (Redfield, Linton, \& Herskovits, 1936). In the context of immigration, acculturation is a reciprocal process whereby receiving societies adapt in varying degrees to new immigrant populations, although immigrants generally go through more cultural change than the receiving society (Berry, 2008). Not all groups or individuals undergo acculturation in the same way. There are large variations in how people seek to engage the process. These variations have come to be known as acculturation strategies (Berry, 1980, 2006).

Berry $(1980,2006)$ described four acculturation strategies that are derived from two basic issues facing an acculturating individual or group: the first issue was the degree to which individuals wish to maintain (or change) their heritage culture and identity (cultural maintenance). The second was the degree to which individuals wish to have contact and participate with other ethno-cultural groups in the larger society, including the dominant one (Berry, 2006; Berry \& Sabatier, 2011). The combination of these dimensions resulted in four acculturation strategies described by Berry (1997) as integration (maintain original culture and interact with other groups), assimilation (relinquish original culture and interact with other groups), separation (maintain original culture and little interaction outside one's own group), and marginalisation 
(no interest in maintaining original culture and reject interaction with other groups).

However, in some instances, the second dimension has been defined differently, either as adopting the host culture, identifying with it, or adapting to it, rather than as interaction with other groups (Berry \& Sabatier, 2011; Lopez-Rodriguez, Navas, Cuardrado, Coutant, \& Worchel, 2014; Maisonneuve \& Teste, 2007). Previous research has demonstrated that adopting the host culture can affect the host populations' perceptions of immigrants (Lalonde \& Cameraon, 1993; Liebkind \& Jasinskaga-Lahti, 2000). Furthermore, a study by Maisonneuve and Teste (2007) demonstrated how adopting the host culture (or not) influenced the host population's perceptions of immigrants, while taking into account the effects of race. An aspect of the present research was to see whether these results could be replicated in a different context. Therefore, the definition that includes adopting the host culture as the second dimension has been used in the current research, and the four strategies were operationalised as: integration (maintain original culture while adopting key aspects of the host culture), assimilation (relinquish original culture, adopt the host culture), separation (maintain original culture and remain aloof from the host culture), and marginalisation (reject both the host culture and original culture).

Previous research has explored attitudes towards acculturation strategies and immigrants in general (Bourhis, Moise, Perreault, \& Senecal, 1997), while other studies have looked at acculturation strategies and attitudes towards specific ethnic minority groups (Lee \& Fiske, 2006; Van Oudenhoven, Prins, \& Buunk, 1998; Maisonneuve \& Teste, 2007). In this article, we asked what influence acculturation strategy has on the host population's perception of immigrants, and to what extent does immigrants' race play a part. While racial categorisation does not in itself necessarily cause prejudice, it has long been associated with racial prejudice both as a cause and consequence (Allport, 1954; Blascovich, Wyer, Swart \& Kibler, 1997; Fiske, Lin, \& Neuberg, 1999), and has been shown to affect how much prejudice and discrimination immigrants may experience (Berry, Kim, Power, Young, \& Bujaki, 1989). As explained below, this can extend to the acculturation strategies that visibly distinct racial minorities are able to pursue when settling into a new country.

\section{Interplay of Acculturation Strategies and Racial Appearance}

Racial appearance may affect how an individual chooses to acculturate to the dominant culture. For example, studies of Australian Indigenous communities in the 1970s (Berry, 1970) found that racial appearance affected participants' attitudes towards their own acculturation behaviours and also toward the dominant Australian society. Berry found the more Aboriginal an individual appeared the more they wanted to pursue assimilation, but the more likely they were to be excluded by the dominant society. He also found that those who appeared the least Aboriginal were more likely to reject the dominant society; however, they were the least likely to be excluded. While Berry's study raises issues about the racial prototypicality of a group and its subsequent effects, the purpose of citing it in the present research is to illustrate how racial appearance can affect acculturation preferences of a majority population for a particular minority group, and it can also affect the acculturation choices of a minority group when deciding how to adapt to a majority culture.

Additionally, immigrant minorities whose racial features are distinct from the host majority, such as Koreans in Canada or Turks in Germany, may be unable to pursue their acculturation strategy of choice, particularly if it is assimilation or integration, because they experience prejudice and discrimination based on their race (Berry et al., 1989). Research conducted by Taillandier and Maisonneuve (2005) in France demonstrated that differentially valued minority groups can be subject to different prejudices as well as to different preferences from the host population for how they should acculturate. The research found that assimilation and segregation (separation) were the host population's preferred choices for immigrants of Asian, Maghrebin, or Turkish origin, while integration was preferred for immigrants from Europe. Particular acculturation strategies have been found to be preferred for 'valued' immigrants, such as integration for French people in Quebec (Montreuil \& Bourhis, 2001), whereas segregation, exclusion, and assimilation were preferred for 'devalued' immigrants (e.g., Haitians in Quebec; Montreuil \& Bourhis, 2001). 'Devalued' immigrants tended to have language and cultural differences, and they also tended to belong to minorities who were of a different racial group to the majority host population.

However, if particular minority groups want to adopt separation as a strategy, this might be an antecedent to prejudice or negative affect based on acculturation strategy rather than racial group. Evidence suggests an effect of acculturation strategy that overrides effects of racial appearance. In a French study that included the four acculturation strategies and three immigrant groups (Moroccan, Congolese, and Vietnamese), Maisonneuve and Teste (2007) examined how the French host population perceived immigrants. The results showed no effect of racial group, but there were significant differences in the perceptions of immigrants who assimilated or integrated when compared with those who separated, with those who separated being rated less positively on warmth, competence, and affect measures. The authors concluded that participants evaluate immigrants more positively when they adopt the host culture compared with those who do not. In the Netherlands, Van Oudenhoven, Prins, and Buunk (1998) conducted research on the Dutch host population's attitude towards immigrants from Morocco and Turkey. They found only an effect of acculturation strategy, with targets who separated being assessed the most negatively, and those who assimilated or integrated the 
most positive, regardless of their nationality or ethnicity, which could also be expected to vary according to racial group.

\section{Social Perception: The Stereotype Dimensions of Warmth and Competence}

The stereotype content model proposes that stereotypes are created around two key dimensions: warmth and competence (Fiske, Cuddy, Glick, \& Xu, 2002). A long line of work on interpersonal and social perception shows the relevance of these two dimensions in social interactions, suggesting that such interactions require answers to two key questions when people meet others. Perceivers want to know the other's intent towards them (positive or negative; this is termed 'warmth') and capability to pursue that intent (termed 'competence'). The model states that particular groups are stereotypically associated with different combinations of warmth and competence that may lead to prejudice or negative affect (Fiske et al., 2002; Lee \& Fiske, 2006).

Lee and Fiske (2006) investigated whether the common perception of 'immigrants' as a generic group (i.e., low in warmth and competence) would change if different immigrant groups were identified by nationality, ethnicity, and socioeconomic status. They predicted that once host populations differentiated between groups, perceptions of immigrants would differ, and assessments of warmth and competence would be made on commonly held, consensual stereotypes. For example, in the United States, East Asian immigrants are stereotyped as competent but cold (Lee \& Fiske, 2006), Italians as warm and friendly (Fiske et al., 2002), and Jewish people as competent but not warm (Fiske et al., 2002). Lee and Fiske's (2006) hypothesis was supported by evidence that perceptions of warmth and competence differed by group, reflecting stereotypes of the original nationality combined with socio-economic status. The current research used the stereotype content model as a tool for investigating the host population's perceptions of immigrants and the extent to which these perceptions are influenced not only by the immigrant's racial or national group, but also by their acculturation strategy.

\section{The Current Research}

Previous research has provided details about stereotypical perceptions of immigrants in the United States according to their national or ethnic origin and socio-economic status (Fiske et al., 2002; Lee \& Fiske, 2006); and furthermore, racially distinct groups have been found to elicit different prejudices and discriminatory behaviours from host populations (Taillandier \& Maisonneuve, 2005; Berry et al., 1989). However, these studies did not take into account the effect of acculturation strategies on how immigrants are perceived and evaluated.

Outside the United States, Van Oudenhoven et al.'s (1998) research in the Netherlands revealed a large main effect of acculturation strategy on Dutch majority members' affective responses to Moroccan and Turkish immigrants, but no effects of the target's racial or national background. However, their research did not measure stereotype based perceptions of warmth and competence that were included in the U.S.-based research. It also did not include a visual image of the immigrant. Because race is perceived visually, we suggest that not presenting an image of the target person could result in low salience of race and may consequently underestimate the effect of race as a category. Maisonneuve and Teste (2007) examined the effects of acculturation strategy and racial/ethnic background on French majority members' affective responses to and ratings of warmth and competence in immigrant minorities. Like Van Oudenhoven et al. (1998), the research revealed a consistent main effect of acculturation strategy, but no effects of racial/ethnic background. However, also like Van Oudenhoven et al. (1998), these studies presented written scenarios with no visual image of the immigrant. Again, it is possible that this method could have underestimated the impact of race as a variable.

The evidence from these studies combines to suggest that acculturation strategies have a consistent effect on hosts' stereotyping of immigrants and their attitudes towards them, and that racial group has little effect. However, before a firm conclusion can be reached regarding the effect of racial group, a stronger manipulation of race should be used. It is possible that using text-based scenarios without incorporating visual primes did not activate race as strongly as it would if an image was included. These studies also did not include a control group, so it is not apparent if the results would have demonstrated an ingroup bias. So, while there is evidence to support the strong influence of acculturation strategy, how much influence racial group has on stereotypical perceptions of warmth and competence in immigrants remains unclear. The current research investigated the effects of both race and acculturation strategy on social perception using the stereotype content dimensions of warmth and competence while priming participants visually for race.

The current studies were conducted in Australia, a country built on immigration. Often, nations that are relatively new to immigration or not accustomed to accommodating many disparate cultures prefer assimilation as an acculturation strategy for immigrants (Kosic, Manetti, \& Sam, 2005). Australia held a policy of assimilation until the 1970s when its immigration policy became one of multiculturalism. With an official multicultural policy, Australian society celebrates and encourages diversity. Immigrants are entitled to maintain their culture and language, and the government is required to support immigrants in maintaining their culture through services and programs (Dandy \& Pe-Pua, 2013). However, as explained below, Australia's population may still show considerable support for assimilation in their attitudes.

According to Klymicka (2012), Australia rates first out of more than 20 other countries on an index of 'Immigrant 
Multiculturalism Policy Scores' and is a good example of a successful multicultural society (Collins, 2013). Berry (1997) reported that populations of multicultural nations tend to prefer integration as a strategy for immigrants. In line with this, if Australia is a truly multicultural nation, we would expect strong endorsement among the population for integration. However, the evidence for this is mixed. Some studies have shown moderately strong public support in Australia for immigrant minorities to maintain their culture (e.g., Ang, Brand, Noble, \& Wilding, 2002; Dandy \& Pe-Pua, 2010), and Dunn (2003) reported that $85 \%$ of the population believes cultural diversity is good for society. However, other studies have indicated significant support among Australians for assimilation, with $46 \%$ of respondents in Sydney believing that Australia is weakened by immigrant groups retaining their old ways (Forest \& Dunn, 2007). To clarify this, one aspect of the current research was to compare acculturation strategies to see which received the most positive approval among Australian participants. In line with the suggestion that Australia is a multicultural society, we tested the hypothesis that Australians would perceive immigrants who integrate more positively compared to those who adopt other acculturation strategies.

Being a multicultural society does not preclude its populace from racism. Research by Mellor (2004) found that despite being a multicultural society 'the tradition of racism towards non-Anglo immigrants continues' in Australia (p. 631), and research by Dunn (2003) found that about one quarter of Australians report the experience of everyday racism. This result is highest among those born overseas, excluding racially white immigrants from the United Kingdom and New Zealand. We therefore tested the hypothesis that there would be a main effect of race on ratings of warmth, competence, and affect, with the European targets (the majority in Australia) being perceived more positively than other racial groups. We also explored the interaction between race and acculturation strategy, as it was possible that acculturation strategy would amplify race-based responses.

Two studies were conducted in which participants viewed scenarios depicting the acculturation strategies of integration, assimilation, separation, and marginalisation in immigrants from three different national or racial groups. Participants then rated the perceived warmth and competence of targets in the scenarios, and their affective response to them. In Study 2, to investigate potential explanations for the results in Study 1, cultural distance was added as another dependent variable. The first study tested the effects of acculturation strategy and race using a small sample from Australia's largest and most diverse city, Sydney. Study 2 then refined the method and recruited a larger and more nationally representative sample. Study 1 used a mixed design where each participant rated four targets from one racial group, each portraying a different acculturation strategy, whereas Study 2 used a fully between-subjects design.

\section{STUDY 1}

\section{Method}

\section{Participants}

Participants ( 56 men, 83 women, 3 non-specified) were recruited from the general population living in Sydney, Australia. Advertisements in local newspapers were followed by letterbox drops. The study was also advertised on Twitter and email. The average age was 45 years (range $=23-$ 76 years). Sixty-three percent were tertiary educated (the Sydney average is $23 \%$ ), and $28 \%$ were first-generation immigrants. Of the $70 \%$ Australian born, almost $40 \%$ had parents who were immigrants. Eighty-five percent of the sample identified as Anglo, British, Caucasian, or European. Overall, the sample was slightly older and more educated than the Sydney averages (Australian Bureau of Statistics, 2008), but the racial heritage and percentage of first-generation immigrants reflects the population, and the sample was considered suitable for this research.

\section{Procedure}

The study was presented as being about what Australians feel might be the best acculturation strategy for new potential citizens. Acculturation was explained as 'a term that describes the process of how people from other cultures adapt to life in a new and different culture'. Acculturation strategy was introduced in non-technical terms as:

\section{Should new immigrants adopt the new culture? Keep their orig- inal culture? Have both? Or is it best to discard their old cul- ture and avoid the new? There are many possibilities. Successful adaptation benefits both the newcomer and the established com- munity.}

The survey was anonymous. Participants completed a demographics questionnaire, then proceeded to the scenarios, with each one followed by the survey questions.

\section{Design}

A 4 (acculturation strategy: assimilation, integration, separation, marginalisation) $\times 3$ (group: Korean, Dutch, Sudanese) mixed experimental design was used, where acculturation strategy was a within-subjects factor and group was a between-subjects factor with random allocation. The dependent variables were affect (liking or disliking of the immigrant), and perceived warmth and competence of the target.

\section{Materials}

Scenarios (manipulation of acculturation strategies). The scenario method developed by Van Oudenhoven et al. (1998) was adapted for this study. Participants were shown four scenarios, each depicting a different target person behaving in accordance with one of each of the acculturation strategies (assimilation, integration, separation, marginalisation). Depending on which racial group the participant was allocated, the scenarios described targets who had immigrated from either Sudan, Korea, or 
the Netherlands (see Appendix A for examples of all four acculturation strategies with the Sudanese group). They were presented as factual stories and included life domains considered important when examining the effects of acculturation: marriage, family, education, work life, and community involvement (Berry, 1984).

Photographs of the individuals from each racial group (African, Asian, European; please see Appendix B) were used to prime race. To control for individual differences between the targets, each photograph was rotated between the scenarios. The different pairings were then randomly allocated to participants so that no one photograph was consistently associated with the same acculturation strategy. The scenarios were presented in random order. Based on research by Eagly and Kite (1987), which found that men were perceived to resemble stereotypes of their nationalities more than women and also to reduce any effects of gender, only male targets were used in the scenarios.

\section{Measures}

Warmth and competence measures. Participants were given a list of adjectives that have been previously identified as traits indicative of warmth (trustworthy, warm, good natured, sincere, friendly, and well intentioned) and competence (competent, efficient, capable, confident, intelligent, and skilful; Fiske et al., 2002; Maisonneuve \& Teste, 2007). The scales were presented as: 'Based on your first impression, please rate how much you agree or disagree with each of the following statements. The man in the story is ... ' Ratings were made on a 7-point Likerttype scale $(1=$ strongly disagree to $7=$ strongly agree $)$. Cronbach's alpha for the warmth scale in this study was .92 and for the competence scale it was .95.

Affect. This measure was adapted from Maisonneuve and Teste (2007) and asked participants to state their opinions on two items: 'I like the man in the story' and 'I would get along with the man in the story'. They were asked to answer using a 7-point Likert-type scale ( $1=$ strongly disagree to 7 = strongly agree). The reliability for this measure was .76.

Manipulation check. To check effectiveness of the manipulations, participants were asked to rate two statements: 'In my opinion the person wants to keep his original culture' and 'In my opinion the person wants to adopt the mainstream Australian culture', using a 5-point Likerttype scale $(1=$ definitely not to $5=$ definitely yes $)$. This check tested the two dimensions of acculturation strategies as we have defined them in this article (maintenance of original culture and adoption of the host culture). Free space was provided at the end of each set of questions, and participants could add further comments about the attitude, behaviour, and potential of the man in the article.

\section{Results}

The data were screened for outliers and checked for univariate and multivariate normality. Of the 174 responses collected, 32 had fewer than $25 \%$ of items completed and were excluded from the sample. A repeated-measures analysis of variance (ANOVA) was performed on the manipulation check data to test that targets who were presented in the scenarios as keeping their own culture (integration, separation) were perceived as such. The results supported this, $F(3,348)=712.59, p<.001$, partial $\eta^{2}=.86$, with assimilation $(M=1.73, S D=.69)$ and marginalisation $(M$ $=1.97, S D=.87)$ receiving significantly lower scores than integration $(M=4.39, S D=.72)$ and separation, which scored the highest $(M=4.92, S D=.27)$, as revealed in post hoc tests with a Bonferroni adjustment of .008. The second ANOVA also supported that targets who were presented as adopting the mainstream Australian culture (assimilation, integration) were perceived as such, $F(3,354)=$ $310.17, p<.001$, partial $\eta^{2}=.72$. Assimilation $(M=4.51$, $S D=.78)$ and integration $(M=3.03, S D=1.07)$ scored significantly higher than separation $(M=1.23, S D=.48)$ and marginalisation $(M=2.64, S D=.98)$. Thus, the manipulation check showed that the acculturation scenarios were perceived as intended.

A mixed 4 within-subjects (acculturation strategy) $\times 3$ between-subjects (group) multivariate analysis of variance (MANOVA) was then performed on the combined DVs of warmth, competence and affect (see Figure 1 for $M$ and $S E$ in each condition). The multivariate result was significant for acculturation strategy, with a large effect size, Pillai's trace $=F(9,108)=30.00, p<.001$, partial $\eta^{2}=.71$. Followup ANOVAs on the separate DVs showed significant differences for how warm, $F(3,348)=69.19, p<.001, \eta^{2}=.37$, and competent, $F(3,348)=44.81, p<.001, \eta^{2}=.28$, targets who used different acculturation strategies were perceived, as well as for how much they were liked, $F(3$, $348)=96.82, p<.001, \eta^{2}=.45$. Pairwise comparisons using Bonferroni adjustment for multiple comparisons (adjusted $p=.006$ ) revealed significant differences in all comparisons, except between assimilation and integration (for warmth, competence, and affect) and between marginalisation and separation for warmth. Immigrants who marginalised or separated were rated as significantly colder, less competent, and were liked less than those who integrated or assimilated. Immigrants who separated were perceived as significantly less warm and competent, and were liked significantly less, than all other strategies with the exception of the comparison with marginalisation for warmth, where the difference was non-significant.

The multivariate result for racial group was also significant but with a small effect size, Pillai's trace $=F(6,230)=$ $2.76, p=.01$, partial $\eta^{2}=.07$. Follow-up ANOVAs on the separate DVs revealed an effect of group on perceptions of warmth, $F(2,116)=6.49, p=.002, \eta^{2}=.11$, and competence, $F(2,116)=4.90, p=.009, \eta^{2}=.08$, as well as how much they were liked, $F(2,116)=6.37, p=.002, \eta^{2}=.10$, with small effect sizes in each case. Pairwise comparisons, again using Bonferroni adjustment for multiple comparisons (adjusted $p=.006$ ), revealed that targets of African origin were perceived as significantly warmer and more competent, and were liked more than European targets. 


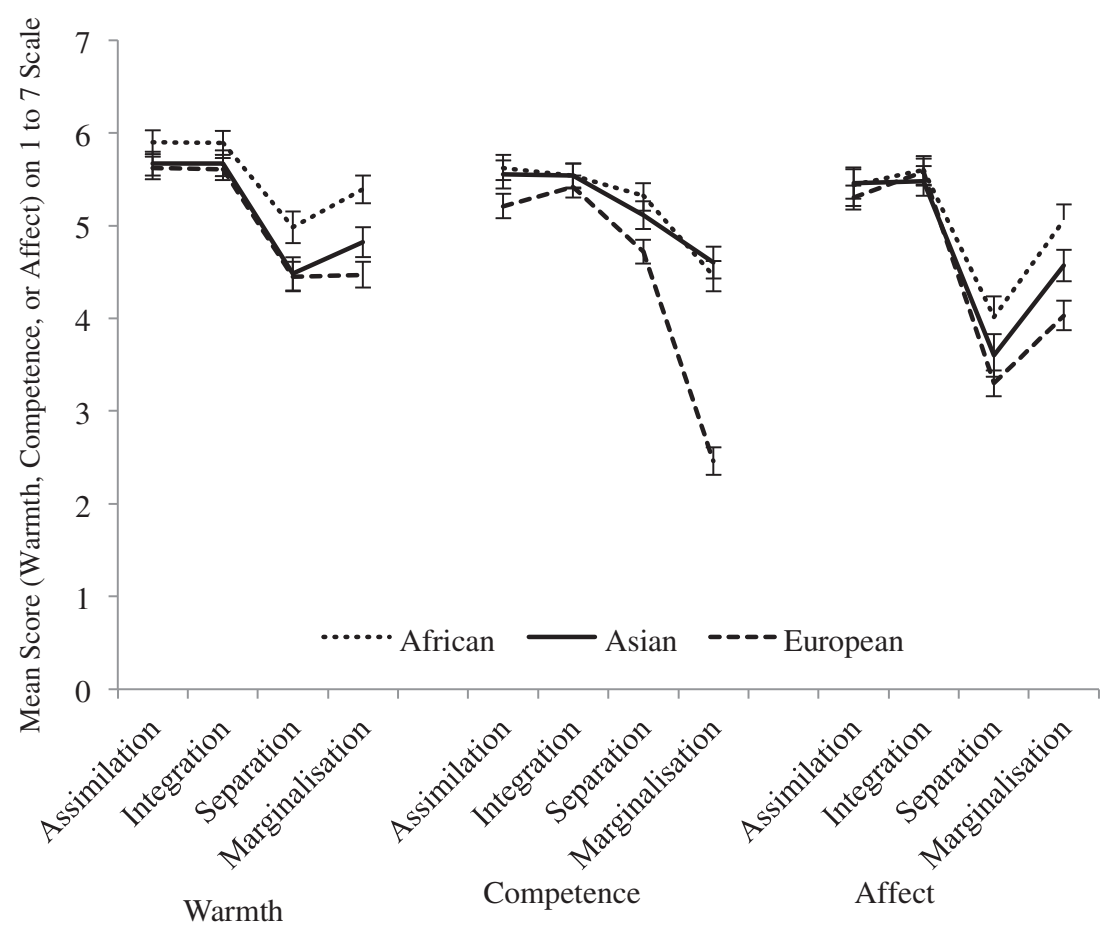

Figure 1

Mean ratings in Study 1 of targets' warmth, competence, and affect towards them when pursuing different acculturation strategies. Error bars are standard errors.

There were no significant differences in responses between African and Asian targets, or between the European and Asian targets.

The MANOVA also revealed a significant multivariate effect for the interaction of acculturation strategy and group, Pillai's trace $=F(18,218)=1.87, p=.02$, partial $\eta^{2}=.13$. Follow-up ANOVAs found no significant interaction effects for the separate DVs.

To check for potential influence of participants' place of birth, we included birthplace (Australia, or not) as a covariate in the analyses and found no significant effects for acculturation strategy, Pillai's trace $=F(9,105)=.42$, $p=.92$ or racial group, Pillai's trace $=F(3,111)=1.73$, $p=.16$. We also considered testing for effects of the participants' own racial heritage, but as $85 \%$ of participants identified with European or British racial heritage, and 9\% did not identify at all, there were insufficient participants who indicated a different racial heritage $(6 \%, n=9)$ to conduct this analysis.

\section{Discussion}

This study investigated the influences of acculturation strategy and racial group on how a host population perceived immigrants. Acculturation strategy was a strong influence on ratings of warmth, competence, and affect, while racial group had little or no effect, despite being primed through the use of photographs of the targets. The results are consistent with previous research of a similar nature (Maisonneuve \& Teste, 2007; Van Oudenhoven et al., 1998), which found that host populations rated immigrant targets more positively or negatively according to their acculturation strategy rather than their racial heritage.

We hypothesised that, as a multicultural society, Australians would respond most positively to immigrants who adopted integration as an acculturation strategy. However, integration and assimilation both prompted more positive responses than separation and marginalisation. This provides mixed evidence regarding support for multiculturalism among the current sample. In line with Berry (1997), the high ratings for integration together with the low ratings for separation illustrate support for multiculturalism. However, targets who assimilated were rated equally positively as those who integrated, and this is at odds with a multicultural view.

The responses indicate that adopting the host culture is interpreted positively, regardless of whether immigrants retain their original culture or not. Cultural distance (how dissimilar cultures are in language, religion, values, and so on) could potentially play a part in these responses. If immigrants are similar in their cultural attributes to the host society because they have adopted similar cultural behaviours and values, then cultural distance may appear low. Conversely, if they separate, then cultural distance may appear high. The perception of cultural distance between cultures has been found to be an important factor in acculturation orientations and outcomes (Berry, 1992; Searle \& Ward, 1990). While there is some evidence to support that dissimilar racial appearance mitigates acceptance of immigrants by a host population (Lalonde \& Cameron, 
1993; Liebkind \& Jasinskaga-Lahti, 2000), it is well established that cultural distance between two groups makes it more difficult for them to adapt to each other (Berry, 2006; Ward \& Kennedy, 1993; Ward \& Searle, 1991). As acculturation is a process of adaptation suggesting different levels of adoption of the host culture, it is possible that an acculturation strategy used by an immigrant may influence their perceived cultural distance from the host society. To investigate this further, cultural distance was included as a dependent variable in the next study, with the hypothesis that acculturation strategy will influence perceived cultural distance between the target and the host population.

We expected a main effect of race with the European group (which reflects the majority of the host population and the participants) being rated more positively than Africans and Asians. This was not supported. While there was an effect of race, it was Africans (a racial outgroup for most participants) who were rated most positively on all the variables. This was a curious finding and is contrary to the usual result of discrimination against outgroups. However, this effect size was small, and could be a result of social desirability concerns, with participants wanting to appear not to discriminate against one of Australia's newest minority groups and so overcompensating in giving high ratings. Given that the sample in Study 1 only represented the city of Sydney, one aim of the second study was to test whether this result would be repeated among a larger and more nationally representative sample, to help generalise the findings.

In Study 1 the different racial groups were labelled by nationality (e.g., Europeans were identified as Dutch, Asian as Korean, African as Sudanese) leaving the possibility that ratings were based on national stereotypes rather than race. We conducted a second study to discover whether similar results would be found with a larger and more representative sample, and to make some methodological refinements. The issues of sample size and representativeness were addressed by recruiting a much larger sample of participants from all over Australia. References to the target's nation of origin and cultural traits such as the language they spoke were removed from the scenarios. This ensured that the photograph depicting racial group was the most salient categorisation option rather than the country of origin. The design was changed to entirely between-subjects, avoiding any possibility that participants might compare strategies.

\section{STUDY 2 \\ Method}

\section{Participants}

A total of 1,123 participants (506 males, 617 females) were recruited Australia-wide via Qualtrics Survey Panel Services. Seventy-two who were not Australian citizens over the age of 18 years were excluded, leaving 1,051 participants (mean age $=54$ years, range $18-87$ years). Twenty- nine percent had immigrant parents, while the majority were Australian-born (73\%), leaving 27\% who were immigrants themselves. This corresponds with the general Australian population, of which $28 \%$ are immigrants (Australian Bureau of Statistics, 2008).

Almost $25 \%$ of participants had a university degree, which is close to the national average, with $31 \%$ studying for or having attained a university degree (Australian Bureau of Statistics, 2008). The majority (90\%) identified as Caucasian, Anglo, or European. Participants with Asian ancestry made up $6 \%$, and the remaining $4 \%$ had ancestry from southern Europe, the Middle East, Africa and India.

\section{Procedure}

The study was presented to participants as an exploration of what the Australian host population believes to be the best behavioural strategy for new immigrants to successfully adapt to life in Australia. The survey was administered online and included demographic questions followed by the scenario and then the dependent measures. Participants were assured of anonymity, and the entire survey took approximately 10 minutes to complete.

\section{Design}

A 4 (acculturation strategy: assimilation, integration, separation, marginalisation) $\times 3$ (racial group: African, Asian, European) between-subjects design was used. The dependent variables were warmth, competence, affect, and cultural distance.

\section{Materials and Measures}

Scenarios and manipulation of acculturation strategies. The Study 1 scenarios were used, but with references to nationality or specific cultural information (i.e., language spoken) removed (see Appendix A). The scenarios included a photograph of the target that was randomly selected from two photographs for each racial group. Pilot testing of the photographs was conducted and, based on pilot data $(N=22)$, the photographs were matched on characteristics of perceived attractiveness, warmth, how engaging they were, and age.

Warmth and competence scales. Participants completed the same warmth and competence measures as in Study 1. The same reliability was obtained for both scales (Cronbach's alpha $=.96$ ).

Affect. Participants answered the same questions as in Study 1. Cronbach's alpha was .92.

Cultural distance. Participants answered the question: 'Culturally, how similar or different do you feel from the person in the story?' and rated their response on a 5-point scale $(1=$ completely different to $5=$ very similar $)$. This measure was adapted from Nesdale and Mak (2003), who asked ethnic minorities to report how similar or different they felt their ethnic background was to the AngloAustralian culture. 


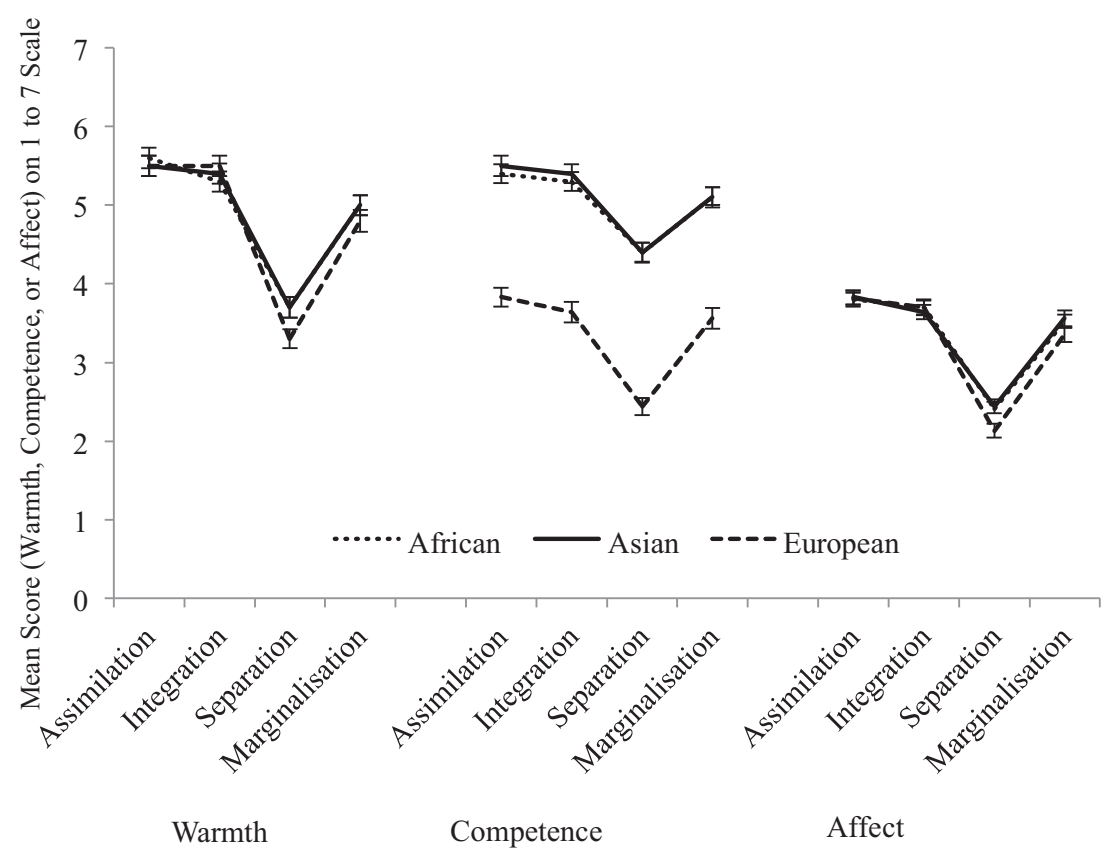

Figure 2

Mean ratings in Study 2 of targets' warmth, competence, and affect towards them when pursuing different acculturation strategies. Error bars are standard errors.

Manipulation check. The same manipulation check was conducted as in Study 1.

\section{Results}

Four separate 4 (acculturation strategy) $\times 3$ (racial group) between-subjects ANOVAs were conducted for warmth, competence, affect, and cultural distance (see Figure 2 for $M$ and $S E$ in each condition), as the multivariate analysis assumptions required for MANOVA were not met for all variables. $\log 10$ transformations were required to meet normality assumptions for the ANOVA; however, other than small differences in the actual $F$ statistic the results using transformed and non-transformed data were the same. We therefore report the untransformed results for ease of interpretation.

\section{Manipulation Check}

We conducted a 4 (acculturation strategy) $\times 3$ (racial group) ANOVA for both manipulation check items. Targets who kept their own culture were perceived as intended, $F(3,992)=555.33, p<.001, \eta^{2}=.62$, with mean scores significantly higher for integration $(M=4.22$, $S D=.76)$ and separation $(M=4.63, S D=.70)$ than strategies that do not maintain their original culture (assimilation: $M=2.06, S D=.99$; marginalisation: $M=2.50$, $S D=.96$ ), as revealed in post hoc tests with a Bonferroni adjustment of .008. The results for adopting the host culture also indicated that the acculturation scenarios were perceived as intended, $F(3,992)=395.05, p<.001, \eta^{2}=$ .53 , with mean scores for assimilation $(M=4.25, S D=.92)$ and integration $(M=3.21 S D=1.00)$ significantly higher than separation $(M=1.43, S D=.88)$. There was no signif- icant difference between integration and marginalisation $(M=3.05, S D=.95)$.

\section{Warmth}

The first ANOVA tested the effects of acculturation strategy and racial group on perceived warmth. The results showed a main effect of acculturation strategy, $F(3,984)=$ $153.85, p<.001, \eta^{2}=.32$. Post hoc tests with a Bonferroni adjustment of .005 revealed that targets who integrated or assimilated were perceived as warmest (with no difference between these two strategies), and targets who separated were perceived as the least warm. There was no significant effect of racial group, $F(2,984)=1.61 p=.20, \eta^{2}=.00$; nor was there an interaction effect, $F(6,984)=1.15 p=.33$, $\eta^{2}=.00$. See Figure 2 for means and standard errors.

\section{Competence}

The second ANOVA tested the effects of acculturation strategy and race on perceived competence. The results showed a main effect of acculturation strategy, $F(3,982)$ $=58.15 p<.001, \eta^{2}=.15$. Post hoc tests with Bonferroni adjustment of .005 found significant differences between separation and all the other strategies. Targets who separated had the lowest scores. Those who assimilated or integrated were rated highest, while marginalisation was rated higher than separation but lower than the other two strategies. There was no significant main effect of racial group, $F(2,982)=.57, p=.56, \eta^{2}=.00$; nor was there a significant interaction effect, $F(6,982)=.99, p=.43$, $\eta^{2}=.00$. 


\section{Affect}

The third ANOVA tested the effects of acculturation strategy and race on affect. The results showed a strong main effect of acculturation strategy, $F(3,984)=171.11, p<.001$, $\eta^{2}=.34$. Post hoc tests with Bonferroni adjustments of .005 revealed that participants had the most positive affect towards targets who assimilated or integrated. Targets who separated were rated significantly lower for affect than all the other strategies. There was no significant effect of racial group, $F(2,948)=2.06, p=.13, \eta^{2}=.00$, nor was there a significant interaction effect, $F(6,984)=1.05$, $p=.39, \eta^{2}=.00$.

\section{Cultural Distance}

The final ANOVA tested the effects of acculturation strategy and race on cultural distance (see Figure 3 for $M$ and $S E$ in each condition). The results showed a main effect of acculturation strategy, $F(3,989)=97.18, p<.001, \eta^{2}=.23$. Post hoc tests with a Bonferroni adjustment of .005 showed targets who separated were rated significantly more culturally distant than other targets, but there were no significant differences between integration and assimilation, or integration and marginalisation. There was a main effect of race, $F(2,989)=4.22, p=.02, \eta^{2}=.008$, and a significant interaction effect, $F(6,989)=3.20, p=.004, \eta^{2}=.02$. However, post hoc tests with a Bonferroni adjustment of .005 did not reveal any significant differences.

A correlational analysis was run between cultural distance and the other three dependent variables. This revealed a large correlation between cultural distance and warmth, $r(996)=.58, p<.01$, cultural distance and affect, $r(996)=.60, p<.01$, and a medium correlation between cultural distance and competence, $r(994)=.46, p<.01$.

To assess whether the racial heritage of the participants had any effect on how they perceived the targets, we re-ran four $3 \times 4$ analyses of covariance (ANCOVAs) with racial heritage (coded as Caucasian, Asian, Middle Eastern, African, Aboriginal or Other) as a covariate. There were small significant effects for warmth, $F(1,904)=4.60, p=.03, \eta^{2}=.005$ and competence, $F(1,901)=10.52, p=.01, \eta^{2}=.01$, but affect was not significant. While there was also a significant effect for cultural distance, $F(1,906)=15.31, p<.001$, $\eta^{2}=.02$, there was no change to the overall results for any of the variables, that is, acculturation strategy consistently had a large effect while the effect of racial group was very small or non-existent, as per the original ANOVAs. To understand whether or not being born in Australia had any effect, four $3 \times 4$ ANCOVAs were performed, this time with Australian born or not as the covariate, with no significant results on any of the variables.

\section{Discussion}

Study 2 aimed to repeat the findings from Study 1 using a larger and more nationally representative sample, amended stimuli, and a between-subjects experimental

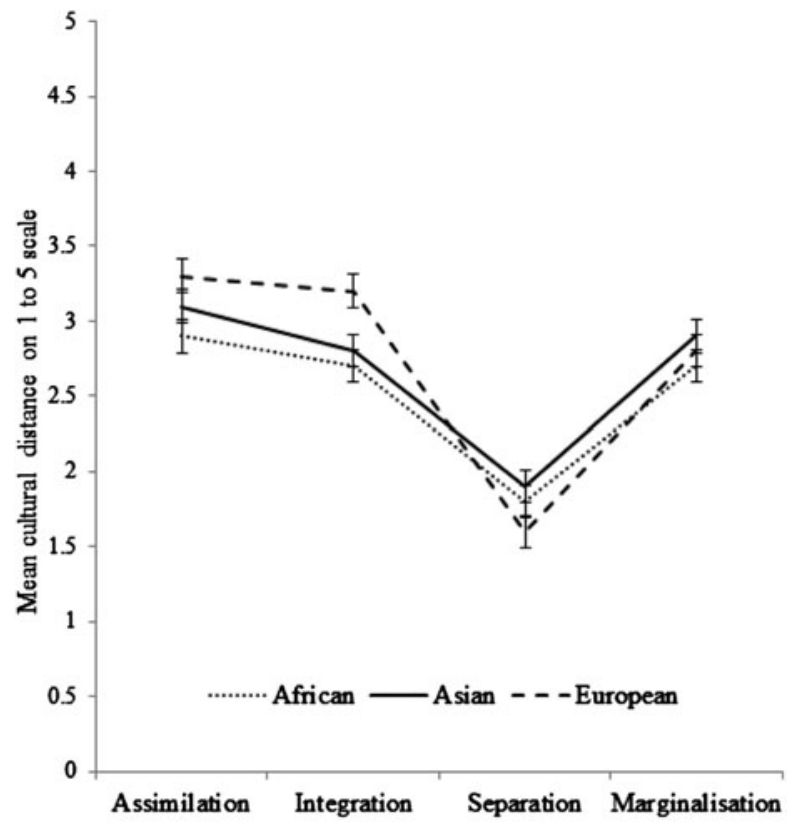

\section{Figure 3}

Mean ratings in Study 2 of targets' cultural distance when pursuing different acculturation strategies. Error bars are standard errors.

design. The aim was also to test the effects of acculturation strategy and race on perceptions of cultural distance.

Like Study 1, there was a significant main effect of acculturation strategy on warmth, competence, and affect, and there were no significant effects of racial group on these variables. The only significant main effect of racial group was on cultural distance. However, this effect was small, and pairwise comparisons did not find any significant differences between individual groups. The small main effect of racial group in Study 1, where African targets were rated more positively than Europeans, was not repeated. Thus, like Study 1, the results from this second study demonstrated consistently strong effects of acculturation strategy and very little or no effect of racial group in host perceptions of immigrants.

Cultural distance was included in Study 2 to assess whether an immigrant's acculturation strategy influences the hosts' perceptions of how culturally distant they seem. The results demonstrated that acculturation strategy does influence perceptions of cultural distance, with targets who did not adopt the host culture but maintained their own culture (i.e., those who chose separation) being perceived as the most culturally distant. Correlational analysis revealed a relationship between cultural distance and the three other variables of warmth, competence, and affect. The relationships between cultural distance, acculturation strategy, and ratings of warmth, competence, and affect raises interesting questions that we will consider below, and suggests directions for future research.

\section{General Discussion}

Social perception and how host communities form impressions of and stereotypes about immigrants is a 
complex process. This article focused on two important influences: acculturation strategy and racial group. The results of two studies showed consistent effects of acculturation strategy on perceptions of immigrants and very small or no effect at all of racial group, either as a main effect or in interaction with acculturation strategy.

In both studies, immigrants who integrated or assimilated were rated most positively. This supports other similar studies from populations in France (Maisonneuve \& Teste, 2007) and the Netherlands (Van Oudenhoven et al., 1998), and expands the investigations to an Australian multicultural context. A desire to integrate or assimilate projects an immigrant's positive attitude towards the mainstream culture and the host society, as these two acculturation strategies both involve adopting aspects of the host culture, and as such may indicate positive intent, which is the basis of the warmth assessment (Fiske et al., 2002; Van Oudenhoven et al., 1998).

The basis of the competence dimension, when perceiving immigrants, is the capability of a target being able to pursue intent, specifically that which involves gaining power and status within the society (Fiske et al., 2002), and suggests to the perceiver a knowledge of the mainstream culture (e.g., language and social customs). This is reflected in the results of both studies, which consistently show the targets who assimilated or integrated being rated higher on this variable, whereas those who separated were perceived as the least competent.

Migrants who separated were perceived the most negatively on warmth, competence, and affect. Furthermore, migrants who separated were perceived as the most culturally distant. There were strong correlations between warmth, competence, affect, and cultural distance, which suggest a link between cultural distance and social perception. If the targets chose integration or assimilation, they were rated as less culturally distant to the participants. Both of these acculturation strategies see migrants adopting the host culture to some degree, and this could be perceived by the mainstream society as a choice to become culturally similar. This is potentially rewarding to the host population as it confirms their values, beliefs, and way of living as correct (Baron \& Byrne, 1997; Byrne \& Clore, 1970). That being said, even targets who chose marginalisation were perceived as more culturally similar than the ones who separated. This indicates that not maintaining one's culture of origin may play a part.

The targets who separated were consistently perceived negatively on all the dependent variables, and they were perceived as being the most culturally distant from the host participants. In fact, the response to separation was so strong that many of the participants voluntarily added comments to support their view, such as: 'I'm not sure why this man is in Australia ... Maybe he would be happier if he went back to Korea' (Participant \#59, Study 1); 'Send him and his family back to Holland' (Participant \#116, Study 1); '. . . it's quite obvious he doesn't want to adapt to the Australian way of life, so my friend ... get back to your own country, not wanted here!' (Participant \#123, Study 2). The results demonstrate participants perceived migrants in a negative light when they maintain their own culture without adopting the host culture.

There is evidence to suggest that when acculturation strategies indicate that immigrants are willing to adopt the host culture are well received, it is reflecting a preference, on behalf of the host population, for maintaining the national identity status quo (Verkuyten, 2009). Integration is the preferred acculturation strategy of multicultural societies, but it can only be truly accepted in societies where there is a sense of identification with the larger society by all groups (Kalin \& Berry, 1995). It has been argued that majority members infer national identification of immigrants when they adopt the host culture (Roblain, Azzi, \& Licata, 2016). The scenarios used in the present research mentioned the target's attitude to formal identification with the larger national group via citizenship, and it seems the participants found this to be an important aspect of integration. While $100 \%$ of the unsolicited comments about the targets who chose integration were positive and encouraging, over $45 \%$ of these comments also revealed an expressed desire that the targets should become Australian and take citizenship. This was across all three racial groups. Examples of these comments are: 'He should become an Aussie' (Participant \#79, African Study 2); 'He may find Australians accept him better if he accepted Australian citizenship' (Participant \#65, African Study 2); 'He should eventually obtain Australian citizenship; otherwise he is on the right track' (Participant \#3, Asian Study 2); 'Why come to Australia if you do not want to become an Australian citizen. After 2 years they do not want to take Australian citizenship send them back home' (Participant \#148, European Study 2).

There were no significant differences between integration and assimilation. This is despite the fact that they are very different acculturation strategies that come with different inferences about the host societies that prefer either one or the other. As previously mentioned, nations new to immigration or not used to a variety of minority cultural groups tend to prefer assimilation, whereas 'settler societies' such as Australia and Canada tend to prefer integration (Berry, Phinney, Sam, \& Vedder, 2006). However, participants in the two present studies positively assessed immigrants on both of these strategies, with no differentiation between the two.

Interestingly, on further investigation into the comments made by participants about migrants who chose assimilation, we found that $38 \%$ were lamenting the fact the targets were not maintaining their culture, suggesting further support for integration. For example: 'Jae should adapt to fit into Aussie society (which he has) but should also maintain his Korean culture (his heritage) ... (Participant \#50, Study 1); 'I think that it's sad to read that Anai thinks that to be a part of Australian culture that he has to ignore his African culture' (Participant \#141, Study 2 ). This is an area that could sustain further research, 
particularly in the Australian context, as further quantitative exploration may reveal nuances of attitudes to explain this equal preference for both assimilation and integration as acculturation strategies.

The results for racial group were not as expected. The Europeans, which is the racial ingroup for the Australian host majority, were not rated more positively than the other groups. This suggests no ingroup bias on the basis of race and also that race did not form a basis for negative responses. However, there is always the chance that participants were influenced by a sense of social desirability, not to be seen as biased towards their own racial group or prejudiced against a racial minority outgroup. The current research used explicit, self-report measures rather than implicit measures, so participants were aware of the responses they were giving.

That being said, techniques were employed to avoid biased responding. Racial group was a between-subjects variable in both of the studies, meaning that participants were not aware there could be comparisons in responses to different racial groups. Furthermore, while race was made salient as a category through visual priming with photographs, the scenarios did not draw overt attention to racial groups.

Although determining the cultural diversity ideology of the host population was not the focus of this research, there is a temptation to conclude from the results that colourblindness, not multiculturalism, is the functioning ideology in Australia. Adopting the host culture was the common element in the presentation of integration and assimilation in this article, and these were the two acculturation strategies that received the most positive assessment. An aspect of the colourblind ideology argues that equality among groups is best gained by downplaying group distinctions (Rattan \& Ambady, 2013), rather than affirming group differences. This refers to cultural distinctions as well as racial group distinctions, and our results did not demonstrate any difference in perceptions between racial groups. Furthermore, it may help explain why the results did not demonstrate any ingroup bias, as research has found participants who endorse colourblindness are most concerned with showing others that they are unbiased (Apfelbaum, Norton, \& Sommers, 2012). An interesting avenue for further research might be investigating colourblindness as a functioning ideology in Australia, with a discussion around what this means for multiculturalism in this pluralistic nation.

\section{Conclusion}

While race is an obvious and immediate visual category upon which we perceive and assess others, in modern immigrant nations it no longer necessarily imparts information about a person's nationality or culture. Our results showed that acculturation strategy, not race, forms a strong basis for positive or negative perceptions of immigrants. This bodes well for an increasingly multiracial society such as Australia. However, the nature of a multicultural society seems more complicated. The results indicated a desire on behalf of the host population for immigrants to adopt the host culture and become culturally similar. True multiculturalism requires acceptance of cultural diversity and tolerance that some immigrants may prefer not to adopt the mainstream culture and some may prefer to separate. The strong negative reaction to separation across all three racial groups of targets in both of our studies indicates that racial differences have less impact than cultural differences. This suggestion is also supported by the strong positive reaction across all three groups to assimilation. However, there was an equally strong positive reaction to integration. This is a good indication that, despite recent turmoil regarding asylum seekers and reports of discrimination towards immigrant minorities, multiculturalism is a functioning diversity ideology in Australia, albeit with room to mature.

\section{Acknowledgements}

This work was supported by Special Projects funding from the School of Behavioural, Cognitive, and Social Sciences, University of New England, Armidale, Australia.

\section{Declaration of Interest}

None.

\section{Appendix A \\ Study 1 Scenarios}

Below are the scenarios from Study 1. All of the scenarios included the name and country of origin of the target. The examples given below are for the Sudanese/African group. Please see Appendix B for the 12 photos (depicting all three groups) that were randomly allocated and rotated with all four acculturation strategies.

\section{Assimilation}

Anai Nimeiri from Sudan in Africa. Anai is originally from Sudan. He moved to Australia around ten years ago, and at that time was apprehensive. He was wondering what life would be like here. He knew Australia and Sudan were quite different.

As it turns out, Anai has a good job with the local council. He has a lot of Australian friends, and he prefers that they call him Andrew. He gets on well with his colleagues at work and sees them regularly outside of work at weekend football matches and at social barbeques. Recently, Anai (Andrew) applied for Australian citizenship. When asked his views on maintaining his Sudanese language, culture, and his children marrying in Australia, he said: 'I've never really wanted to hang on to the Sudanese culture. I think you have to become part of the culture you live in. I have children and I don't want to 
hinder them in their development here. In Australia we should speak English and I do not care if my children do no speak a work of the Sudanic languages, or if my daughter grew up to marry an Australian, as long as he was a good person. I've felt Australian for a long time. I do not feel the need to maintain ties with Sudan.'

The first paragraph was the same for all four scenarios, with differences indicating the strategy beginning in the second paragraph:

\section{Integration}

Umar has a good job and has made friends at work, and he says he enjoys introducing his Australian colleagues to his favourite traditional Sudanese food. Umar has also developed many friendships within the Sudanese community in his local area. When asked his views on maintaining his Sudanese language, culture and his children marrying in Australia, he said: 'My wife and I are fairly traditional and we stick to all Sudanese customs, but we are not isolated from our environment. I am very happy for my children to speak English, but I hope they retain their Sudanese language. It enhances their knowledge about their heritage. I would like my son to learn the family traditions of Sudanese culture, but he has also taken an interest in the game of rugby league, which is fine. It would please me very much if my daughter grew up to marry a Sudanese man, but I would also understand if she chose to marry an Australian. I have recently been thinking of taking Australian citizenship, but at the moment I do not really see the advantage of doing so. I am Sudanese, in spite of the fact that I like living in Australia and I like the Australian people.'

\section{Separation}

Sadiq has a good job with a government department. However, apart from his work, he has almost no contact with other Australian people. His social life is built around the Sudanese community in his local area. When asked about maintaining his Sudanese culture, language and about his children marrying in Australia, he said: 'My wife and I are very traditional and we stick to all Sudanese customs. This is very important to us. We have sent our children to school back in Sudan, so they know what it is to be Sudanese. Otherwise, they might become too Australian. I want them to be able to have a good future in their own country. I hope when my daughter grows up, she will want to marry a Sudanese man. It is very important culturally, that she does. If I want to socialise with friends I prefer to go to the Sudanese Club. I am always welcome there and the people have similar values to mine. I often find that Australians are very forthright and I find it difficult to relate to Australians about anything. I do not want to become Australian. It is important that my family and I maintain Sudanese citizenship.'

\section{Marginalisation}

Dahab has had a few jobs and is currently working. He has contact with Australian people at his job, but he rarely socialises with them. He does not live in an area with many other Sudanese people either, nor does he seek out other Sudanese immigrants. He prefers to keep to himself. He seems to have abandoned the Sudanese culture but does not feel entirely at home with the Australian culture. When asked about his views on maintaining his Sudanese culture, language and his children marrying in Australia, he said: 'I've never wanted to adhere to Sudanese culture. Why would you want to do that when you're living here? But I don't think the Australian culture is right for me either, even though I try to adjust and fit in, because I have children, so it's the right thing to do for them. I do not care if my children never speak any of the Sudanic languages and only speak English, and it doesn't bother me if my daughter grows up to marry an Australian. But Australian people are much more outspoken than I am used to - I find it hard to find common ground with Australians generally. On the other hand, I don't want to pursue Sudanese cultural interests. It seems silly to waste my time on such things now. I might become an Australian citizen. I haven't given it much thought.

\section{Study 2 Scenarios}

Below are the scenarios from Study 2. They differ from the scenarios in Study 1 in that they do not specify country of origin or language. The examples given are for the European group. Please see Appendix B for the six photos (depicting all three groups) that were randomly allocated and rotated with all four acculturation strategies.

\section{Integration}

Dereck has lived here in Australia for about five years. $\mathrm{He}$ has a good job and has made friends at work, and he says he enjoys introducing his Australian colleagues to his favourite traditional food. Dereck has also developed many friendships with people from his original culture in his local area. When asked his views on maintaining his original language, culture and descendency, he said: 'My wife and I are fairly traditional and we stick to our traditional customs, but we are not isolated from our environment. I am very happy for my children to speak English, but I hope they retain their original language too. It enhances their knowledge about their heritage. I would like my son to learn the family traditions of our original culture, but he has also taken an interest in the game of rugby league, which is fine. It would please me very much if my daughter grew up to marry a man who was from our culture, but I would also understand if she chose to marry an Australian. I have recently been thinking of taking Australian citizenship, but at the moment I do not really see the advantages of doing so. I want to retain my original citizenship, in spite of the fact that I like living in Australia and I like the Australian people.' 


\section{Assimilation}

Dereck moved to Australia around five years ago, and he now has a job with a local business. He has a lot of Australian friends and gets on well with his colleagues at work. He sees them regularly outside of work at weekend football matches and at social barbeques. Recently, Dereck applied for Australian citizenship. When asked about maintaining his culture, language and descendency, he said: 'I've never really wanted to hang on to my original culture. I think you have to become part of the culture you live in. I have children and I don't want to hinder them in their development here. In Australia we should speak English and I do not care if my children do not speak a word of our original language, or if my daughter grew up to marry an Australian man, as long as he was a good person. I've felt Australian for a long time. I do not feel the need to maintain ties with my original country.'

\section{Separation}

Dereck has lived in Australia for almost five years and he has a steady job. However, apart from his work, he has almost no contact with other Australian people. His social life is built around his own cultural community in his local area. When asked about maintaining his culture, language and descendency, he said: 'My wife and I are very traditional and we stick to our own customs. This is very important to us. We have sent our children to good schools back in our original country, so they know what it is to be part of our culture. Otherwise, they might become too Australian. It is essential that they retain our original language. I want them to be able to have a good future in their own country. I hope when my daughter grows up, she will want to marry a man from our country of origin. It is very important culturally, that she does. If I want to socialise with friends I prefer to go to my local cultural club. I am always welcome there and the people have similar values to mine. I often find that Australians are very forthright and I find it difficult to relate to Australians about anything. I do not want to become Australian.'

\section{Marginalisation}

Dereck has lived in Australia for about five years. He has had a few jobs and is currently working. He has contact with Australian people at his job, but he rarely socialises with them. He does not live in an area with many other people of his original culture, nor does he seek out other immigrants. He prefers to keep to himself. He seems to have abandoned his original culture but does not feel entirely at home with the Australian culture. When asked about his views on maintaining his culture, language and descendency he said: 'I've never wanted to adhere to my original culture. Why would you want to do that when you're living here? But I don't think the Australian culture is right for me either, even though I try to adjust and fit in, because I have children, so it's the right thing to do for them. I do not care if my children never speak the language of my original culture and only speak English, and it doesn't bother me if my daughter grows up to marry an Australian. But Australian people are much more outspoken than I am used to - I find it hard to find common ground with Australians generally. On the other hand, I don't want to pursue aspects of my original culture. It seems silly to waste my time on such things now. I might become an Australian citizen. I haven't given it much thought.' 


\section{Appendix B}
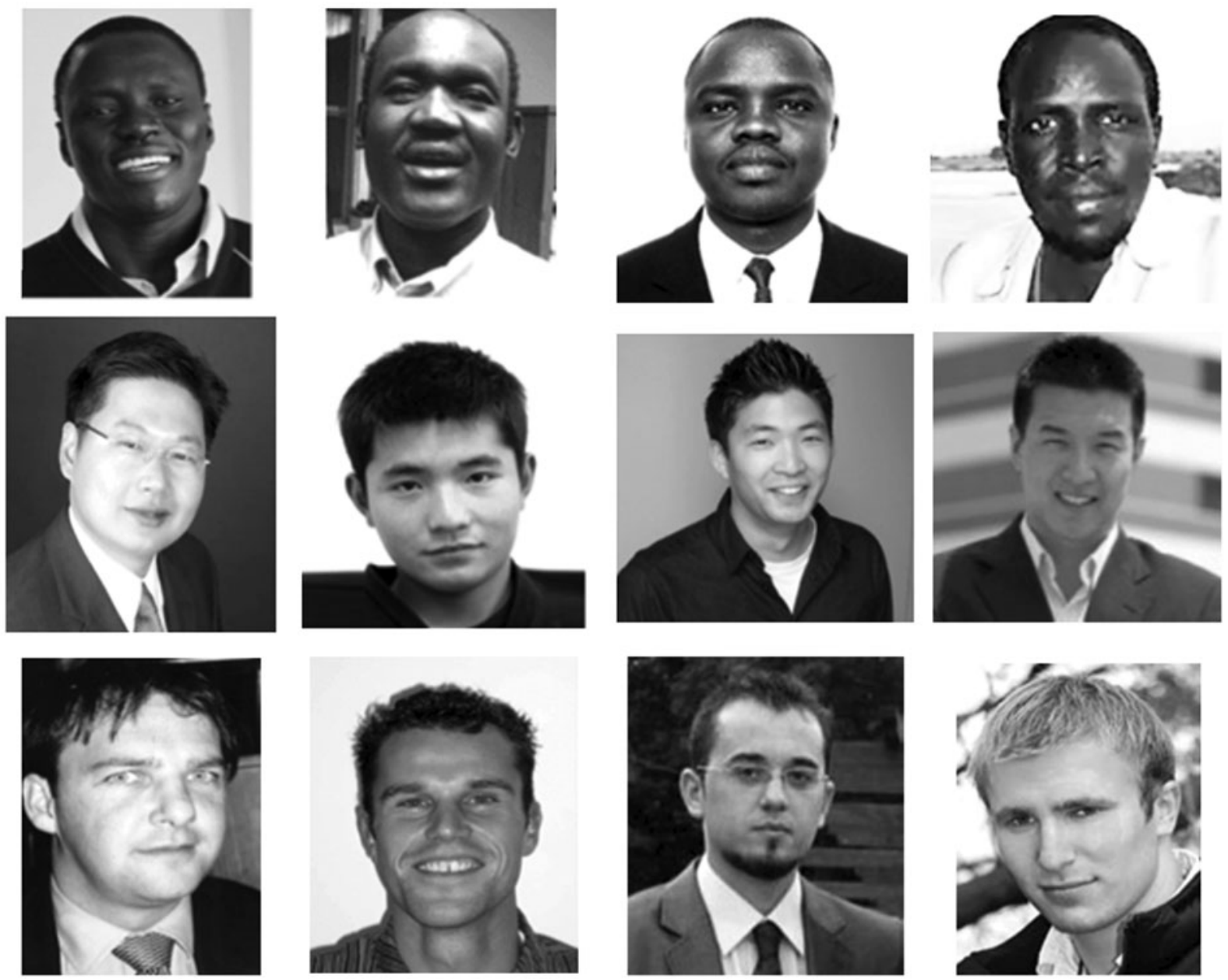

Photographs used in Study 1. 


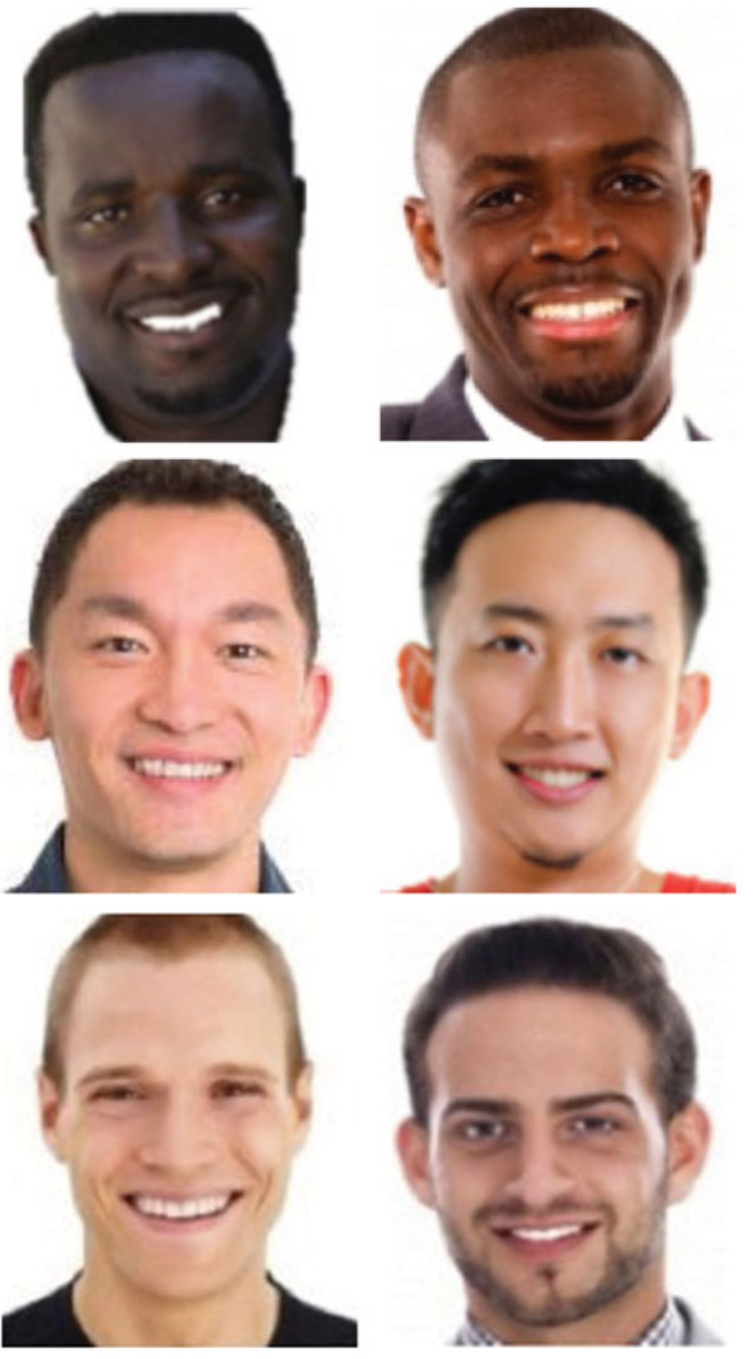

Photographs used in Study 2.

\section{References}

Apfelbaum, E., Norton, M., \& Sommers, S. (2012). Racial colourblindness: Emergence, practice, and implications. Current Directions in Psychological Science, 21, 205-209.

Allport, G.W. (1954) The nature of prejudice. Reading, MA: Addison-Wesley.

Ang, I., Brand, J., Noble., G., \& Wilding, D. (2002). Living diversity: Australia's multicultural future. Sydney, Australia: Special Broadcasting Services Corporation.

Australian Bureau of Statistics. (2008). 1301.0: Year book Australia, 2008. Retrieved from www.abs.gov.au/ausstats/

Bamshad, M., Wooding, S., Watkins, W., Ostler, Batzer, M., \& Jorde, L (2003). Human population genetic structure and inference of group membership. American Journal of Human Genetics, 72, 578-589.

Baron, R., \& Byrne, D. (1997). Social psychology (8th ed.). Boston, MA: Allyn and Bacon.

Berry, J.W. (1970). Marginality, stress and ethnic identification in an acculturated Aboriginal community. Journal of Cross Cultural Psychology, 1, 239-252.
Berry, J.W. (1980). Acculturation as varieties of adaptation. In A. Padilla (Ed.), Acculturation: Theory, models and some new findings (pp. 9-25). Boulder, CO: Westview Press.

Berry, J.W. (1984). Multicultural policy in Canada: A social psychological analysis. Canadian Journal of Behavioural Science, $16,353-370$.

Berry, J. W. (1992). Adaptation and acculturation in a new society. International Migration, 30, 69-86.

Berry, J.W. (1997). Immigration, acculturation, and adaptation. Applied Psychology: An International Review, 46, 5-68.

Berry, J.W. (2006). Contexts of acculturation. In D. Sam \& J.W. Berry (Eds.), The Cambridge handbook of acculturation psychology (pp. 27-42). New York, NY: Cambridge University Press.

Berry, J.W. (2008). Globalisation and acculturation. International Journal of Intercultural Relations, 32, 328-336.

Berry, J.W., Kim, U., Power, S., Young, M., \& Bujaki, M. (1989). Acculturation attitudes in plural societies. Applied Psychology: An International Review, 38, 185-206.

Berry, J. W., Phinney, J.S., Sam, D.L., \& Vedder, P. (2006). Immigrant youth: Acculturation, identity, and adaptation. Applied Psychology, 55, 303-332.

Berry, J., \& Sabatier, C. (2011). Variations in the assessment of acculturation attitudes: Their relationships with psychological wellbeing. International Journal of Intercultural Relations, $35,658-669$.

Blascovich, J., Wyer, N., Swart, L., \& Kibler, J. (1997). Racism and racial categorization. Journal of Personality and Social Psychology, 72, 1364-1372.

Bourhis, R.Y., Moise, L.C., Perreault, S., \& Senecal, S. (1997). Towards an interactive acculturation model: A social psychological approach. International Journal of Psychology, 32, 369-386.

Byrne, D., \& Clore, G. (1970). A reinforcement-affect model of evaluative responses. Personality: An International Journal, 1, 103-128.

Collins, J. (2013). Multiculturalism and immigrant integration in Australia. Canadian Ethnic Studies, 45, 133-149.

Dandy, J., \& Pe-Pua, R. (2013). Beyond mutual acculturation: Intergroup relations among immigrants, anglo-Australians, and indigenous Australians. Zeitschrift fur Psychologie, 221, 232-241.

Dunn, K. (2003, February). Racism in Australia: Findings of a survey on racist attitudes and experiences of racism. Paper presented at The Challenges of Immigration and Integration in the European Union and Australia conference, Sydney, Australia.

Eagly, A., \& Kite, M. (1987). Are stereotypes of nationalities applied to both women and men? Journal of Personality and Social Psychology, 53, 451-462.

Fiske, S., Cuddy, A.J.C., Glick, P., \& Xu, J. (2002). A model of (often mixed) stereotype content: Competence and warmth respectively follow from perceived status and competition. Journal of Personality and Social Psychology, 82, 878-902. 
Fiske, S., Lin, M., \& Neuberg, S. (1999). The continuum model, ten years later. In S. Chaiken \& Y. Trope (Eds.), Dual-process theories in social psychology (pp. 231-254). New York, NY: Guildford Press.

Forest, J., \& Dunn, K. (2007). Constructing racism in Sydney, Australia's largest ethniCity. Urban Studies, 44, 699-721.

Kalin, R., \& Berry, J.W. (1995). Ethnic and civic self-identity in Canada: Analyses of 1974 and 1991 national surveys. Canadian Ethnic Studies, 27, 1-15.

Kawakami, K., Dion, K., \& Dovidio, J. (1998) Racial prejudice and stereotype activation. Personality \& Social Psychology Bulletin, 24, 407-416.

Kosic, A., Manetti, L., \& D. Sam. (2005). The role of majority attitudes towards out-group in the perception of the acculturation strategies of immigrants. International Journal of Intercultural Relations, 29, 273-288.

Kurzban, R., Tooby, J., \& Cosmides, L. (2001). Can race be erased? Coalitional computation and social categorization. Proceedings of the National Academy of Sciences of the United States of America, 98, 15387-15392. Retrieved from www.pnas.org/ doi/ 10.1073/pnas.251541498

Kymlicka, W. (2012). Multiculturalism: Success, failure, and the future. Washington, DC: Migration Policy Institute.

Lalonde, R., \& Cameron, J. (1993). An intergroup perspective on immigrant acculturation with a focus on collective strategies. International Journal of Psychology, 28, 57-74.

Lee, T., \& Fiske, S. (2006). Not an outgroup, not yet an ingroup: Immigrants in the stereotype content model. International Journal of Intercultural Relations, 30, 751-768.

Liebkind, K., \& Jasinskaja-Lahti, I. (2000). The influence of experiences of discrimination on psychological stress: A comparison of seven immigrant groups. Journal of Community and Applied Social Psychology, 10, 1-16.

Lopez-Rodriguez, L., Navas, M., Cuadrado, I., Coutant, D., \& Worchel, S. (2014). The majority's perceptions about adaptation to the host society of different immigrant groups: The distinct role of warmth and threat. International Journal of Intercultural Relations, 40, 34-48.

Maisonneuve, C., \& Teste, B (2007). Acculturation preferences of a host community: The effects of immigrant acculturation strategies on evaluations and impression formation. International Journal of Intercultural Relations, 31, 669-688.
Mellor, D. (2004). The experiences of Vietnamese in Australia: The racist tradition continues. Journal of Ethnic and Migration Studies, 30, 631-658.

Montreuil, A., \& Bourhis, R.Y. (2001). Majority acculturation orientations toward valued and devalued immigrants. Journal of Cross-Cultural Psychology, 32, 698-719.

Nesdale, D., \& Mak, A. (2003). Ethnic identification, self-esteem and immigrant psychological health. International Journal of Intercultural Relations, 27, 23-40.

Rattan, A., \& Ambady, N. (2013). Diversity ideologies and intergroup relations: An examination of colorblindness and multiculturalism. European Journal of Social Psychology, 43, $12-21$.

Redfield, R., Linton, R., \& Herskovits, M.J. (1936). Memorandum for the study of acculturation. American Anthropologist, $38,149-152$.

Roblain, A., Azzi, A., \& Licata, L. (2016). Why do majority members prefer immigrants who adopt the host culture? The role of perceived identification with the host nation. International Journal of Intercultural Relations, 55, 44-54.

Searle, W., \& Ward, C. (1990). The prediction of psychological and sociocultural adjustment during cross-cultural transitions. International Journal of Intercultural Relations, 14, 449-464.

Taillandier, A., \& Maisonneuve, C. (2005) Mise en évidence d'une norme de non racisme dans la mesure des orientations d'acculturation de la communaute d'accueil. Le Cahiers Internationaux de Psychologie Sociale, 3-4, 33-55.

Verkuyten, M. (2009). Support for multiculturalism and minority rights: The role of national identification and out-group threat. Social Justice Research, 22, 31-52. doi:101.1007/s11211-008-0087-7

Van Oudenhoven, J., Prins, K., \& Buunk, B. (1998). Attitudes of minority and majority members towards adaptation of immigrants. European Journal of Social Psychology, 28, 9951013.

Ward, C., \& Kennedy, A. (1993). Acculturation and cross-cultural adaptation of British residents in Hong Kong. Journal of Social Psychology, 133, 395-397.

Ward, C., \& Searle, W. (1991). The impact of value discrepancies and cultural identity on psychological and sociocultural adjustment of sojourners. International Journal of Intercultural Relations, 15, 209-224. 